\title{
Correction to: Acute Mesenteric Ischemia in the Elderly Patient
}

Luís Filipe Pinheiro, Henrique Alexandrino, and Beatriz Costa

Correction to: R. Latifi et al. (eds.), Emergency General Surgery in Geriatrics, Hot Topics in Acute Care Surgery and Trauma, https://doi.org/10.1007/978-3-030-62215-2_18

This chapter was initially published with incorrect Figure 18.9. This figure has now been updated with this erratum.

\section{FULL RESOURCES}

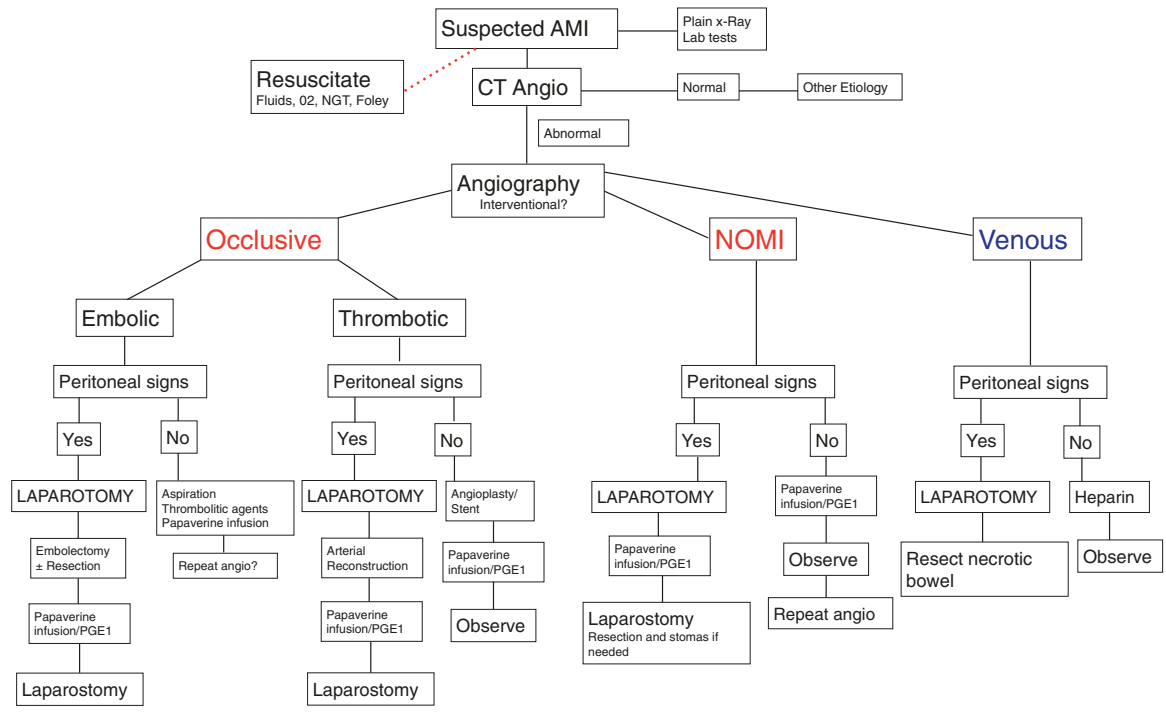

Fig. 18.9 Algorithm for management of acute mesenteric ischemia in a full resources setting

The updated online version of the chapter can be found at https://doi.org/ 10.1007/978-3-030-62215-2_18 